\title{
A teoria do equilíbrio dinâmico em geomorfologia
}

\author{
Marisa Matos Fierz \\ FFLCH-USP
}

p. $605-629$

\section{revista}

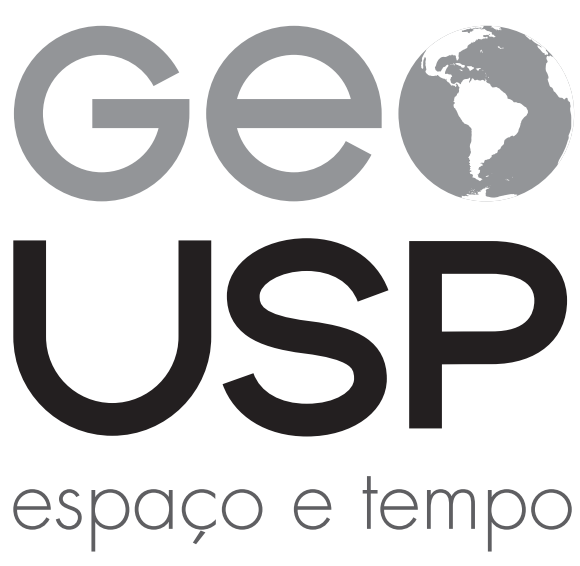

Volume $19 \cdot n^{\circ} 3(2015)$
Como citar este artigo:

FIERZ, M. M. A teoria do equillbrio dinâmico em geomorfologia. Geousp - Espaço e Tempo (Online), v. 19, n. 3, p. 605-629, mês. 2016. ISSN 2179-0892.

Disponível em: URL: http://www.revistas.usp.br/geousp/ article/view/107614. DOI: http://dx.doi.org/10.11606/ issn.2179-0892.geousp.2015.107614.

\section{(c) (i) (2)}

Este artigo está licenciado sob a Creative Commons Attribution 4.0 License. 


\title{
A teoria do equilíbrio dinâmico em geomorfologia
}

\section{Resumo}

objetivo deste artigo é melhor apreender e explicar, em toda sua complexidade, a teoria do equilibrio dinâmico, que tem sido usada na geografia há anos. Muitas derivações são encontradas, muitas associações são feitas; entretanto, não se menciona a real intenção para a qual foi criada, muito menos se a explica de forma clara e objetiva - nem mesmo o próprio autor da teoria do equilibrio dinâmico, Hack (1960). Geralmente, o que se encontram são subjetividades sobre as condições de equilibrio dinâmico relacionadas às mudanças de elementos sobre a superfície, mas pouco sobre o objeto para o qual ela foi elaborada, ou seja, o relevo. Todavia, não se pretende aqui esgotar o assunto, tampouco avaliar se os termos estão corretos ou não, mas retomar uma teoria tão importante para o desenvolvimento da ciência geomorfológica.

Palavras-chave: Geomorfologia. Equilibrio dinâmico. Geografia. Fragilidade ambiental. Termodinâmica.

\section{The theory of dynamic equilibrium in geomorphology}

\begin{abstract}
The purpose of this article is to explain and better understanding, in all its complexity, the theory of dynamic equilibrium, which has been used in geography long time. Many derivations are found, many associations are made, however, the real intent for which it was created is not mentioned, much less explained clearly and objectively even by the author himself quotes the theory of dynamic equilibrium Hack (1960). What lies are usually subjectivities on the conditions of dynamic equilibrium related to changes of elements on the surface, but little about the object for which it was designed, ie relief. However, it isn't intended here to exhaust the subject nor assess whether the terms are correct or not, but return to a theory so important to the development of science geomorphology.
\end{abstract}

Keywords: Geomorphology. Dynamic equilibrium. Geography. Environmental sensitivity. Thermodynamic. 


\section{Introdução}

A teoria do equilibrio dinâmico derivou dos princípios relacionados à teoria geral dos sistemas. Com base na correlação existente entre os elementos do estrato geográfico, a teoria do equilibrio dinâmico representa uma evolução dos estudos geomorfológicos que se baseiam nos preceitos sistêmicos da teoria geral dos sistemas.

Hack (1960) descreve a situação das teorias na sua época destacando as teorias do ciclo geomórfico de Davis, bem como a teoria de Penck (1953) e a teoria da pediplanação de L. C. King (1953). O autor relata que tais teorias são também conceitos cíclicos e abordam o desenvolvimento da paisagem em estágios que são dependentes e fechados, bem como dependentes das descrições das taxas de variação da posição do nível de base.

A teoria do equilibrio dinâmico foi sistematizada por Hack em 1960, muito embora outros tantos autores, sobretudo Gilbert, já tivessem tratado do assunto. Isso ocorre frequentemente com as teorias, muitas discussões antecedem sua criação. Foi o que ocorreu também com a teoria geral dos sistemas, bastante criticada antes de ser definitivamente proposta por Bertalanffy na década de 1950. Menciona-se o enfoque sistêmico, que já havia sido discutido muito antes, por exemplo, por naturalistas, como Humboldt, que participava das pesquisas de Gilbert, como aquele relata em sua obra, Cosmos, ou este (1877), que também falou sobre a importância dos sistemas.

\section{O início, o desenvolvimento e as principais aplicações da teoria do equilí- brio dinâmico}

Falar de equilibrio dinâmico de um sistema, a priori, nos remete a uma análise das teorias sobre evolução das formas. Na bibliografia estrangeira, foram encontrados vários artigos que discorrem sobre essa teoria. Assim, além de buscar as descrições nos textos originais de Hack (1960) e Gilbert (1877), consultaram-se outros autores considerados importantes para o entendimento dessa teoria.

Dessa forma, há autores estrangeiros cujas proposições muito contribuíram para o desenvolvimento da teoria em questão e para entendimento da evolução das formas na superfície terrestre e, consequentemente, da geomorfologia e das concepções utilizadas até hoje. Entre os principais, destacam-se: Davis (1899), Gilbert (1877, 1890), Hack (1960, 1965, 1973, 1975) Higgins (1975), Schumm (1975), Schumm e Lichty (1965), Thorn e Weldford (1994), Daniels e Hammer (1992), entre outros.

Uma alternativa aproximada para a interpretação da paisagem é através da aplicação do princípio do equilibrio dinâmico para relações espaciais com o sistema de drenagem. Assume-se a relação espacial como um sistema erosional onde todos os elementos da topografia estão mutuamente ajustados e estão rebaixando na mesma taxa. As formas e processos estão em estado estável do balanço e devem ser consideradas como independente do tempo. As diferenças das características de formas são, portanto, explicadas em termos de desenvolvimento evolucionário teorético tal como descrito por Davis (Hack, 1960, p. 85). 
Hack explica que o princípio do equilibrio dinâmico era aplicado para o estudo das formas, tanto por Gilbert (1877, p. 123) quanto por Davis (1909, p. 257-261, 239; 1899, p. 488491; 1909, p. 86-98). Na época, Strahler (1950a, p. 676) tinha destacado o princípio do equilibrio dinâmico em termos mais modernos, aplicado para paisagens. $O$ conceito requer um estado de balanço entre forças opostas de modo que elas operem em taxas iguais e seus efeitos se anulem mutuamente para produzir o estado estável, no qual a energia está continuamente entrando e saindo do sistema. As forças opostas devem ser de vários tipos. Por exemplo, um leque aluvial estaria em equilibrio dinâmico se os depósitos derramados da montanha atrás dele fossem depositados exatamente na mesma taxa em que foram removidos por erosão de superfície do próprio leque. Similarmente, a vertente estaria em equilibrio se o material lavado descesse a face e removesse os sedimentos desses topos, onde estariam sendo balanceados exatamente pela erosão (Hack, 1960).

Hack compara ainda a explanação de Gilbert a de Davis sobre a evolução das formas. $\mathrm{Na}$ explicação de Gilbert, sobre aplainamento lateral, envolve-se o equilibrio dinâmico das forças existentes atualmente na base da drenagem e na relação entre essas forças sobre as rochas. Já a teoria de Davis assume que o aplainamento lateral ocorre em qualquer base de drenagem com a passagem do tempo, com respeito às normas da geologia. Hack (1960) destaca que o conceito de aplainamento no contexto do ciclo geográfico de Davis atentava para as relações racionalizadas entre as coisas, que mudavam ao longo do tempo e, portanto, não poderiam ser observadas ou medidas. Na transferência do esquema de ideias que envolvem o espaço para o esquema que envolve o tempo, Davis ignorou as relações espaciais citadas por Gilbert que validavam o conceito.

As superfícies de aplanamento são produzidas por rebaixamento dos canais dos rios em certas circunstâncias, mas não há razão para acreditar que tais superfícies se ampliam através do tempo como relevo está sendo rebaixado, simplesmente como uma consequência da redução na vertente. Por outro lado, isso é como um produto de agradação, e a competência do sistema de drenagem transferindo a destruição dessa bacia de drenagem que pode ser ampliada (Hack, 1960, p. 83).

Em relação ao desenvolvimento do sistema, Hack considera que o geomórfico está em um sistema aberto que tende ao equilibrio no balanço das forças que regem o modelado. $\bigcirc$ modelo desenvolvido por Hack é baseado no princípio de que as formas refletem o balanço entre a resistência do material submetido à erosão e à energia erosiva dos processos ativos. A teoria do equilibrio dinâmico diz respeito aos processos constantes que ocorrem na evolução do relevo em suas diversas formas e provocam a sua variação dinâmica natural. Sua proposição considerou que um sistema de paisagem está sempre em direção a um estado de equilibrio dinâmico e estável, independente do tempo, com possibilidades de predições, no qual um ajustamento se faria entre massas e energias, resultando um sistema de relevo em steady state, estado estável.

A premissa básica do sistema (Hack, 1960, p. 81), é a de que as paisagens e os processos que as formam são parte de um sistema aberto, que se encontra em estado estável de balanço. Dessa premissa, pode-se assumir o seguinte: 
a) existe um balanço entre os processos de erosão e resistência das rochas (Hack, 1960, p. 86);

b) todos os elementos são erodidos na mesma taxa (Hack, 1960, p. 85);

c) as diferenças e as características da forma são explicáveis em termos de relações espaciais no qual os modelos geológicos são a primeira consideração (Hack, 1960, p. 85).

Outra ideia é a de que processos atuais são os que modelam a paisagem atual (Hack, 1960, p. 80); um teste para reconhecer feições históricas seriam os depósitos ou as formas sem harmonia com os processos do presente (Hack, 1965, p. 64).

Hack (1960, p. 81) não propriamente desenvolveu um modelo de mudança que ocorre ao longo do tempo em resposta às variações das condições ambientais, mas também reconheceu que mudanças ocorrem, assim como as condições de equilibrio variam, mas sustenta a ideia de que isso não é necessário para assumir o tipo de mudança evolucionária prevista por Davis. No entanto, ele considera variações no relevo em diferentes casos de balanço entre taxas de soerguimento e de erosão:

a) a taxa de soerguimento é balanceada pela taxa de erosão; se forem taxas altas, uma alta topografia do relevo será formada e mantida tanto quanto se as taxas se mantiverem constantes;

b) a taxa de soerguimento decresce para zero - o relevo é decrescido e, eventualmente, a elevação e a depressão topográfica também; os sulcos se formam mais no entorno (Hack, 1960, p. 95);

c) a taxa de soerguimento aumenta - o relevo é reerguido para manter a taxa de erosão (Hack, 1960, p. 86); o autor defende que tanto quanto os movimentos diastróficos são graduais, são também balanceados pela atividade erosiva; a topografia se manterá num estado de balanço; e admite que, se os movimentos diastróficos forem repentinos, devem ser preservadas formas relíquias na paisagem, até que um novo equilibrio seja ativado (Hack, 1960, p. 86; 1965, p. 8).

A teoria do equilibrio dinâmico explica as formas topográficas e as diferenças entre elas na maneira que deve ser independentemente do tempo. A teoria consiste em que as relações entre as rochas e os processos como existem no espaço. As formas podem mudar somente com a energia aplicada para os sistemas de mudanças. Isso é obvio, entretanto, a energia de mudanças erosionais através do tempo e em diante deve mudar as formas (Hack, 1960, p. 94).

Schumm e Lichty (1965), em crítica ao sistema de equilibrio dinâmico proposto por Hack, destacam que esse conceito é sinônimo dos sistemas físicos descritos por Von Bertalanffy, para quem "o passado é, então, lembrado e ocultado". Contudo, depois de excluído o tempo do seu sistema, Hack reconsidera-o, dessa forma: "Isso é obvio, entretanto, que a energia erosional muda através do tempo e, portanto, as formas devem mudar". As mudanças na energia erosional podem ser desencadeadas por muitos fatores, dos quais o diastrofismo ou a mudança climática são os mais evidentes. Além disso, com a passagem do tempo, a modifi- 
cação erosional das formas afetará a energia erosional. Então, isso parece ser impossível para a exclusão do tempo e a história de consideração das formas, exceto no estudo puramente empírico das relações entre variáveis, as quais devem ou não refletir na causalidade (Schumm; Lichty, 1965, p. 111).

No modelo de ajustamento de Hack (1960, p. 86), assume-se o balanço existente entre os processos de erosão e a resistência das rochas, como elas são soerguidas ou desaparecem por diastrofismo tal que a energia potencial necessária é variável pela erosão para o balanço de soerguimento. Com essa modelagem, diferenças na paisagem são consideradas diferenças na geologia da resistência das rochas, rios e gradientes, bem como o relevo será mais elevado em rochas mais resistentes. Com o tempo, diferentes formas, tais como formato de cristas, vão sendo moldados em rochas resistentes, o que promove colúvios de taxas similares. Diferenças em formas de uma área para outra, incluindo o relevo, o perfil de forma dos rios, os vales de secção atravessada, as planícies fluviais, as formas de topos, são explicadas em termos de diferenças nos leitos rochosos, em seus componentes materiais e em como são trabalhados nas vertentes e nos rios.

Segundo Hack (1975), o princípio do equilíbrio dinâmico, quando utilizado para explicar as feições da paisagem, não é um modelo evolucionário em si, tal como o ciclo geográfico de Davis. Entretanto, o equilibrio dinâmico é um princípio universal, que pode ser utilizado para explicar feições e problemas específicos da paisagem, ao assumir que a paisagem se desenvolve durante um longo período de contínuo desgaste. $\bigcirc$ conceito pode ser testado e comparado com o ciclo de erosão múltipla pelo exame da variedade de feições específicas na paisagem, como o fez o próprio autor no Vale do Shenandoah, na Virgínia (EUA).

Apesar de haver um confronto entre as ideias discutidas nas duas teorias - a do ciclo geográfico e a do equilibrio dinâmico -, pode-se considerar que, enquanto Davis, com o ciclo geomórfico, considerava que o nivelamento das cordilheiras dos Apalaches provinha do resultado cíclico do rejuvenescimento, para Hack (1960) isso seria resposta das manifestações diferentes de resistência do material que compunha aquelas formas em relação às forças erosivas. Assim, para Hack, se a resistência do material for igual à resistência da força de erosão, o resultado será relevo elevado. Muito embora as explicações fossem diferentes, ambos convergiam no sentido de encontrar explicações mais adequadas à evolução do relevo.

$\bigcirc$ equilibrio dinâmico também é chamado de estado estável (steady state). Segundo Langbein e Leopold (1964, p. 784 apud Bull, 1975), a mais provável distribuição da energia em certos sistemas geomórficos pode ser equilibrada, considerando-se o sistema geomórfico como um sistema aberto em estado estável: "O princípio do estado de equilíbrio dinâmico é baseado na ideia de que, quando em equilibrio, a paisagem deve ser considerada parte de um sistema aberto em estado estável de balanço, no qual toda vertente e toda forma é ajustada em si” (Hack, 1965, tradução nossa).

Hack avançou na ideia de modelo para o desenvolvimento da paisagem. Este assume que há ajustes mútuos de todos os elementos topográficos e que esses elementos estão erodindo na mesma taxa. A taxa pode variar consideravelmente dependendo do tipo de material. As formas e os processos estão em estado estável de balanço e são independentes do tempo (Daniels; Hammer, 1992). 
Pela definição supracitada, as formas relictuais ou as paisagens não seriam reconhecidas, mas Hack reconheceu formas como terraços e planícies costeiras. $\bigcirc$ equilibrio dinâmico requer um estado de balanço entre as forças opostas, que operam em taxas iguais e, efetivamente, se cancelam para produzir o estado estável. Isso significa que, em um leque aluvial, se perde material tanto quanto se deposita.

De acordo com Thorn e Weldford (1994), entre os vários conceitos de equilibrio em geomorfologia, provavelmente o equilibrio dinâmico é o mais citado e certamente o único cuja origem é puramente geomorfológica. A versão do significado do conceito geomórfico foi desenvolvida por Gilbert (1877), em um trabalho sobre as montanhas Henry (EUA). Embora pareça que esse autor tenha desenvolvido tal ideia enquanto trabalhava em um extenso artigo sobre o Colorado, na verdade ele escreveu suas noções sobre equilibrio dinâmico sucintamente:

Erosão é mais rápida onde a resistência é menor e, portanto, como as rochas moles são desgastadas, as duras são deixadas à mostra. A diferenciação contígua até um equilibrio é alcançada pela lei da gravidade. Quando o nível periódico da ação erosiva depende da declividade, se torna igual ao nível de resistência que depende do caráter da rocha, ocorrendo igualdade de ação (Gilbert, 1877, p. 115-116 apud Thorn; Welford, 1994, p. 681).

Gilbert (1877) elaborou suas ideias no seguinte trecho sobre "ação de igualdade de interdependência":

A tendência de igualdade da ação, ou para o estabelecimento do equilibrio dinâmico, já tem sido colocada fora de discussão do princípio de erosão e de esculturação, mas um desses resultados mais importantes não tem sido notado.

Das condições significativas as quais determinam a taxa de erosão, tem-se a denominação e quantificação de água corrente, vegetação, textura da rocha e declividade, somente a última está reciprocamente determinada pela taxa de erosão. Declividade originada em soerguimentos, ou nos deslocamentos da crosta terrestre pela qual as montanhas e continentes são formados, mas isso recebe uma distribuição em detalhes de acordo com as leis da erosão.

Em qualquer lugar onde ocorre qualquer das condições dos agentes erosivos torna a ter localmente força excepcional. Essa força local fica diminuída pela taxa de reação da erosão em declividade. Qualquer vertente faz parte de um conjunto que quando recebe água ocorre a perda da vertente, descartando a própria água, ou seja, perda de material para a baixa vertente. A aceleração de cima para baixo é retardada, diminuindo a declividade do elemento no qual o distúrbio é originado; e como a declividade é reduzida a taxa de erosão é da mesma forma reduzida.

Mas o efeito não para por aqui. $O$ distúrbio de transferência de material não cessa até que tenha alcançado os limites da base da drenagem. Para cada base, todas as linhas de drenagem se unem na linha principal e dali vai para os tributários. Assim como cada membro do sistema é influenciado por todos os outros. Existe interdependência por toda parte do sistema (Gilbert, 1877, p. 123-124, tradução nossa). 
Na citação acima, nota-se que Gilbert já fazia uso de termos em linguagem de análise sistêmica, com relação à interdependência dos elementos da paisagem geomorfológica e a interação entre os elementos que formam a cobertura do relevo, diante dos processos originados em vertentes, sobretudo, influenciados pela lei da gravidade e pela composição do material que sustenta o relevo.

○ conceito de equilibrio dinâmico proposto por Gilbert assemelhava-se ao balanço das forças de equilibrio que aparecem em dinâmica, mas, por analogia, especialmente à derivação formal, tem várias outras características:

- descrição do comportamento interno como sistema (base de drenagem), que constitui a descrição dos processos tal como o estado de condição;

- dependente da escala (limitado para base de drenagem), porque deva terminar o ajuste da borda da base não imediatamente em evidência própria;

- está de acordo com a transferência de massa (especialmente de energia);

- engloba a imatura expressão da forma (isto é, declividade); claramente, o conceito de equilibrio dinâmico proposto por Gilbert deve ser respeitado como de origem unicamente geomorfológica.

Hack (1960, p. 85) sugere que muitos elementos da paisagem estão em equilibrio dinâmico com os processos que agem sobre eles: as formas e os processos encontram-se em estado estável de balanço e devem ser considerados como independentes do tempo. Ele compara essa condição com que o solo rebaixa na superfície na mesma taxa de rebaixamento da borda dos horizontes de solos que se movem para baixo no regolito (Nikiforoff, 1959' apud Schumm; Lichty, 1965), e continua com o seguinte argumento:

A teoria do equilibrio dinâmico explica formas topográficas e as diferenças entre elas na maneira que deve ser dita por ser independente do tempo. A teoria diz respeito às relações entre as rochas e processos como elas existem no espaço. As formas podem mudar somente com a energia aplicada para as mudanças dos sistemas (Hack, 1960, p. 85).

Thorn e Welford (1994) consideram que, embora o conceito de Gilbert tenha recebido pouca atenção durante o período denominado pelo modelo davisiano de desenvolvimento da paisagem, seu trabalho se tornou o fio condutor e influenciou diversos outros autores, como Strahler, na década de 1950. Enquanto esse período de fluorescência da geomorfologia contém muitas ideias que apresentam (e são) críticas ao desenvolvimento do pensamento científico na geomorfologia, os autores voltaram a atenção para as várias interpretações do equilibrio dinâmico.

Thorn e Welford (1994) criticam Hack argumentando que o conceito de equilibrio dinâmico foi restabelecido em 1960, não obstante na forma híbrida. Infelizmente, a versão revisada da contribuição de Gilbert para o pensamento geomórfico confundiu o assunto pela utilização dos termos "equilibrio dinâmico" e "estado estável". Assim, em 1960, Hack comparou o antigo e restrito conceito geomórfico com a restrita termodinâmica:

A suposição era criada pela observação e mapeamento das formas na região e poderia ser explicada com base nos processos que estão agindo hoje através do estudo das relações entre o fenômeno como está distribuído no espaço. $\bigcirc$ con-

1 NIKIFOROFF, C. C. Reappraisal of the Soil. Science, v. 129, n. 3343, p. 186-196, 23 jan. 1959. 
ceito de equilibrio dinâmico serviu como base filosófica das formas para esse tipo de análise. A paisagem e os processos moldados são considerados parte de um sistema aberto no estado estável do balanço no qual cada vertente e cada forma é ajustada pela outra (Hack, 1960 apud Thorn; Welford, 1994).

Na opinião de Thorn e Welford (1994), embora, na ocasião, Hack (1975, p. 94-95) tenha distinguido equilibrio dinâmico e estado estável, o erro original foi repetido por Hack e outros, como na mistura apresentada a seguir; "o estado estável é possível no sistema aberto e difere do estado estacionário do equilibrio estático dos sistemas fechados. Nós deveríamos então, equacionar o termo estado estável com equilibrio dinâmico em geomorfologia como definido por Hack (1960)" (Leopold; Langbein, 1962 apud Thorn; Welford, 1994).

Para Hack (1975), Gilbert não teve coragem de sistematizar a ideia do equilißrio dinâmico, então ele tomou a iniciativa e, como estava à procura de uma teoria que explicasse a evolução do relevo em qualquer nível topográfico, passou a estabelecer a teoria do equilibrio dinâmico como uma forma adequada para essas imputações.

Vários conceitos diferentes de equilibrio dinâmico têm sido englobados em um só. Essa noção incorporada de estado estável definiu o aspecto do estado do relevo e agregou a noção de estado estável definido com relação ao estado atrativo em um sistema termodinâmico aberto, que deve referir-se à energia e massa, sendo um estado estacionário definido apenas com relação à energia e ao equilibrio estático, entendido como o corpo dinâmico que está estagnado ou em descanso e no qual a soma das forças atuantes é zero, nula.

O equilibrio dinâmico não tem sido equiparado somente a um estado estável, mas também ao quase equilibrio e, com isso, derivado empiricamente de um significado, por exemplo: evolução da paisagem é uma evolução na natureza do termo, mantendo o significado, enquanto e através do tempo essencialmente o equilibrio dinâmico ou quase equilibrio. Esses argumentos foram baseados na expressão estatística de entropia, conceituada pela analogia com os termos termodinâmicos. No ajuste dos rios, argumentava-se que é rápida a comparação para taxas de elevação, uma reivindicação de que os períodos de internalização e a relaxação de tempo são breves. Assim, rios suspensos sobre posição significativa atentam qualitativamente para a quase estatística ou quase estado de equilibrio.

Sobre esse assunto Hack (1960) cita Leopold e Maddock (1953), que consideram os níveis da drenagem em relação à geometria hidráulica do canal. Seus estudos de entalhamento da drenagem e secção com dados que indicam como os modelos se ajustam na relação entre as variáveis: largura, profundidade, velocidade e perda de material sedimentar na dissecação dos níveis topográficos dos cursos d'água. Eles concluíram que os conceitos de Mackin, de níveis altimétricos, não podem ser demonstrados pela consideração dos dados do entalhamento da drenagem, de forma que utilizaram o termo quase equilibrio em referência para ao equilibrio nos canais observados por eles, em toda a drenagem estudada. Eles reconheceram que esse equilibrio é distinto do proposto por Davis e Mackin por meio dos conceitos de variações altimétricas da drenagem.

Schumm e Lichty (1965), buscando encontrar uma melhor explicação para o equilibrio dinâmico, escreveram o artigo denominado "Time, space, and casuality in geomorphology". A distinção entre a causa e o efeito no desenvolvimento das formas é uma função do tempo e espaço (área), porque os fatores que determinam o caráter das formas podem ser dependentes ou independentes das mudanças variáveis como os limites do tempo e do espaço. Modera- 
damente, durante longos períodos de tempo, por exemplo, a morfologia do canal do rio é dependente da geologia e do ambiente climático, mas, durante curto período de tempo, o canal morfológico é uma variável independente do canal hidráulico.

Os autores estenderam suas associações de equilibrio dinâmico com os conceitos de gradiente de Davis: "A níveis do instante de tempo se referem a curto período do tempo cíclico durante o qual a condição de variação altimétrica ou equilibrio dinâmico existe". Introduziram os conceitos de tempo cíclico, tempo gradual e tempo estável numa demonstração atenta para a compatibilidade dos conceitos de evolução de Davis, os quais refletiram em uma declaração de Hack sobre tempo independente e, essencialmente, na perspectiva de Gilbert. Esse artigo é profundamente importante na história da geomorfologia, mas a noção de equilibrio é a menos dependente do tempo, que era adicionado a outra dimensão geomórfica, para a maneira pela qual o conceito é tratado. A natureza do problema é evidente na seguinte citação:

Durante o espaço de tempo estável, o verdadeiro estado estável deve existir em contraste com o equilibrio dinâmico e tempo de equilibrio [...]. A paisagem, durante esse instante ou período do tempo, está verdadeiramente em tempo independente porque eles não mudam, e tempo e relevo inicial têm sido novamente eliminados como variáveis independentes. Durante esse instante somente a água e os sedimentos descartados do sistema são variáveis dependentes [...]. Obviamente que a condição de estado estável não é aplicável para toda a base de drenagem (Schumm; Lichty, 1965, p. 115; Schumm, 1975).

Schumm e Lichty (1965) atentaram para a resolução de algumas controvérsias consideradas na paisagem durante diferentes instantes de tempo. $\bigcirc$ tempo necessário para a denudação da paisagem era subdividido em tempo cíclico, declividade e tempo estável (Figura 1). Os autores estenderam a associação do tempo e do espaço com o equilibrio dinâmico com o conceito de ciclo de Davis: "o instante de tempo [...] se refere a curto espaço de tempo cíclico, o qual dura certa condição de tempo”.

Figura 1 - Diagrama da mudança do gradiente do canal em diferentes instantes
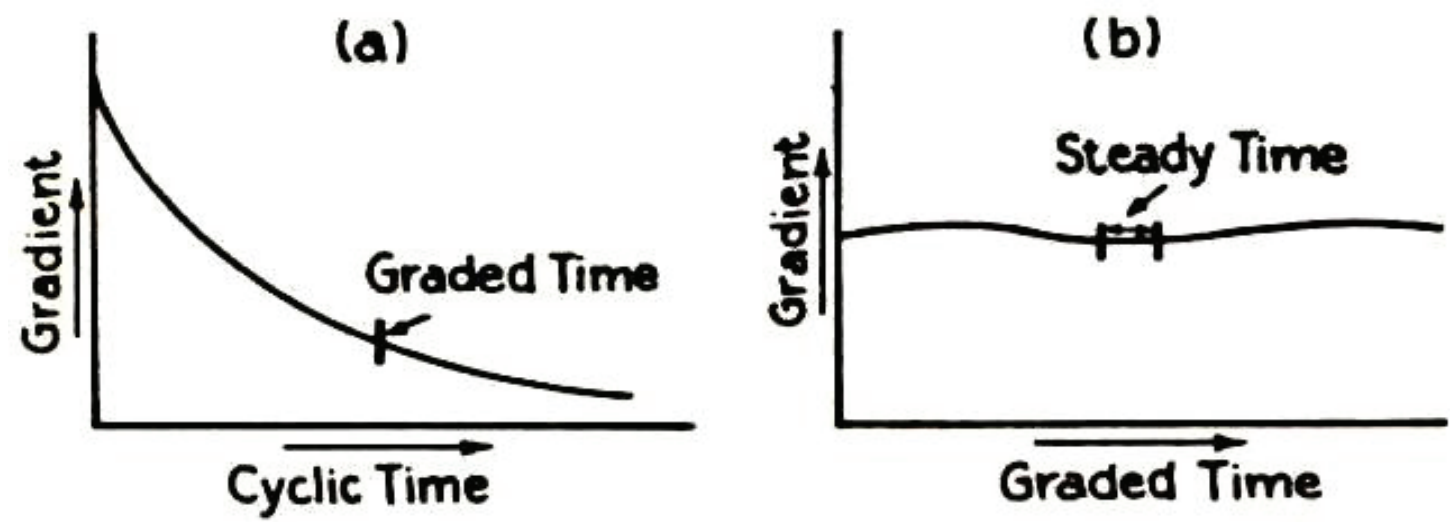

(a) Redução progressiva do gradiente durante o tempo cíclico. Durante o tempo equilibrado, uma pequena fração do tempo cíclico, o gradiente se mantém relativamente constante.

(b) Flutuações do gradiente sobre e abaixo do significado durante o "período de tempo".

gradiente é constante durante o breve instante do tempo estável.

fonte: Schumm e Lichty (1965). 
Schumm e Lichty (1965) destacam a importância da distinção de três escalas temporais separadas, a cíclica ou do tempo geológico, que abrange os milhões de anos necessários para completar um ciclo erosivo, a escala de tempo de equilibrio (grade), termo utilizado por Davis para mostrar uma condição de balanço essencial entre a corrosão e a deposição, usualmente atingido no estágio maduro de desenvolvimento do relevo.

Se a preocupação fosse explicar os termos do ciclo geográfico de Davis, como chama Higgins (1975), aos conceitos derivados da teoria geral dos sistemas termodinâmicos, o ciclo seria identificado como um sistema fechado, que recebe toda energia externa e somente alcança o equilibrio e o estado estável no final, quando o processo estiver lento. Já o conceito de equilibrio dinâmico de Gilbert é citado como um exemplo de sistema aberto que requer um fluxo de energia contínuo para manter o estado estável. Tais análises podem ser muito utilizadas, mas elas tendem a confundir particularmente os objetivos da pesquisa para uma teoria geral aceitável do desenvolvimento da paisagem, e eles também têm sido muito mal interpretados.

Higgins (1975) cita ainda a ideia de Lee Wilson, que descreve que existem duas formas de equilibrio dinâmico: o estado estável e o crescimento. $\bigcirc$ crescimento negativo pode resultar em um tipo de desenvolvimento evolutivo da paisagem concebido por Davis.

Tais aplicações podem nos ajudar a entender o que acontece em pontos particulares no tempo e no espaço - a relação entre os processos e as formas que são improváveis. Entretanto, eles não podem ser substituídos por observações cuidadosas de campo, para determinar quais sequências de formas têm ocorrido atualmente e em várias configurações tectônicas e climáticas na Terra.

Para Higgins (1975), a principal falha que ainda temos nas teorias do desenvolvimento das formas é a de que a maioria dos estudos no campo geomórfico tem interpretado mal a relação entre a forma e o processo, por deixarem de reconhecer que, em muitas partes do mundo, há volumosas formas de paisagens que são relíquias formadas por processos curtos operando no local.

Morisawa (1965, p. 209) diz que, quando a força tectônica é menor ou maior do que os processos denudacionais, há um desequilibrio da ação. Segundo o autor, o desequilibrio é temporário desde que haja uma tendência ao equilibrio dessas duas forças. Se o soerguimento é rápido e a erosão é lenta, o relevo se eleva rapidamente. A energia de elevação do relevo causa forças erosivas até eles estarem em balanço com as forças tectônicas. Já se as forças denudacionais são mais fortes do que as forças tectônicas, a degradação será gradualmente vagarosa porque o rebaixamento do relevo e a energia finalmente levam a um equilibrio da ação com tectonismo.

$\bigcirc$ estado de equilibrio deve ocorrer apenas enquanto o tectonismo está enfraquecendo e a degradação está crescendo ou vice-versa. Isto é, em estado transitório, desde que a Terra seja dinâmica. Nem é o equilibrio estático, porque a influência é contínua termal, química, magnética e outros tipos de forças agem na e com a Terra. Um exemplo disso seria a isostasia (Morisawa, 1965, p. 209).

A erosão, iniciada por um soerguimento, reduz a superfície da terra e o material é depositado em áreas baixas. Isso resulta em resposta positiva da base de deposição contínua para o lado mais baixo. Assim, ambas, a erosão e a deposição, são reforçadas como são os movimentos crustais. Reajustes isostáticos devem ser imediatos ou tardios. Um vagaroso retorno ocorre quando o reajuste isostático requer um nível de valor. $\bigcirc$ soerguimento de retorno isostático 
demorado, causando renovada erosão, suporta o modelo davisiano, em que, intermitentemente, os soerguimentos resultam níveis de erosão em diferentes elevações. Contínuos retornos isostáticos suportam o modelo penckiano de mudanças das porcentagens do soerguimento para denudação. De acordo com a presente análise, ambos os modelos devem ser esperados na historia geomórfica da região.

$\bigcirc$ mesmo autor enfatiza que, quando as forças erosionais agem sobre material terrestre de resistências diferentes, deve haver um desequilibrio temporário da ação e da forma. Entretanto, há uma tendência à lenta estabilização em forma de equilibrio pela força e pela resistência. Por exemplo, um rio se ajusta na vertente para somente para se suprir da energia necessária a mover a carga erodida. A propósito, os gradientes hidrográficos se distinguem em diferentes tipos de material, e um equilibrio de ação entre resistência e energia é alcançado. No mesmo sentido, na praia um equilibrio da onda de energia e resistência do material é alcançado e demonstrado pela escarpa de praia. Vertentes escarpadas (em microescala) são encontradas em praias onde os materiais estão mais resistentes ao movimento das correntes.

Dessa forma, onde os materiais são mais resistentes, eles causam um crescimento temporário na energia. Para Morisawa (1965), isso pode significar que há uma tendência a uma taxa de equilibrio na natureza. $\bigcirc$ equilibrio está entre forças, ou entre força e resistência e é expresso pelas formas da terra.

Schumm e Lichty (1965) propõem um método para conciliar conflitos entre visões relacionadas à mudança temporal em geomorfologia, com relação à teoria apresentada por Hack (1960) e aos estudos que enfatizavam as investigações sobre as mudanças ambientais, em longo prazo, e a análise do equilibrio dinâmico aplicada às formas de relevo. Para os autores, isso poderia gerar uma dúvida sobre a existência de níveis de cimeira concordantes, como reflexos de antigas superfícies de aplainamento mais extensas. Schumm e Lichty (1965) acreditavam que existia a possibilidade de não se compreender a função do tempo nos sistemas geomórficos e afirmavam acreditar que as distinções entre causa e efeito na modelagem das formas de relevo dependem do lapso de tempo envolvido e da magnitude do sistema geomórfico considerado. De fato, as dimensões da mudança temporal e espacial e as relações de causa e efeito podem ser obscurecidas ou mesmo revertidas, e o próprio sistema pode ser descrito diferentemente.

Para Gregory (1992), em primeiro lugar, na escala de tempo, que pode ser de centenas ou de milhares de anos - durante os quais existe uma condição de ajuste ou de equilibrio dinâmico -, e a escala de estabilidade, da ordem de um ano ou menos, pode existir um verdadeiro estado estacionário. Em segundo lugar, estava a explicação concomitante do status das variáveis geomórficas de acordo com a escala temporal que estava sendo analisada. Assim, uma variável que seja dependente em uma escala temporal pode ser independente em outra. Para ilustrar, Schumm e Lichty (1965) apresentam uma avaliação da paisagem em bacias hidrográficas.

Schumm (1975), como já havia demonstrado no artigo anterior, escrito juntamente com Lichty, continua a criticar outros modelos de evolução geomórfica. Reafirma que a maioria dos modelos de evolução geomórfica é insatisfatória para os termos curtos de interpretação e são ainda muito simplificados, por serem baseados em informações muito limitadas, por exemplo: a extrapolação de taxas de denudação de uma década de dados para mil ou milhão de anos da evolução da paisagem, baseada em suposições de lentas mudanças, que nem devem estar corretas (Gage, 1970² apud Schumm, 1975).

2 GAGE, M. The tempo of geomorphic change. Journal of Geology, v. 78, p. 619-625, 1970. 
Schumm (1975) afirma também que o tempo gasto para a denudação da paisagem era subdividido em ciclos, classificados em períodos de tempo estável. A categoria de tempo em ciclos são intervalos de duração geológica, ou seja, o período de tempo necessário para a evolução denudacional de uma paisagem. Por exemplo, durante esse período, o que se espera é o decréscimo exponencial do gradiente fluvial, um componente da paisagem que reflete as mudanças no sistema fluvial. Entretanto, o ciclo de tempo pode ser subdividido em períodos de tempo e períodos de tempo estável.

Durante as classes de tempo, o gradiente avaliado será relativamente constante. Mas será através do tempo que ocorrerão variações sobre esse significado. $O$ período de tempo existe conforme a definição de gradiente, como expressou Mackin (1948). Durante o curto período de tempo estável, não houve mudança. Quando se considera uma paisagem ou seus componentes, isso ajuda a pensar em como a paisagem é alterada durante os períodos de tempo considerados abaixo (Figura 2). Em resumo, o período de tempo referido, bem como cíclico ou geológico, pode ser representado em duração pela curva de Davis, que mostra a evolução da erosão na paisagem.

\section{Figura 2 - Modificação do conceito de ciclo geomórfico}

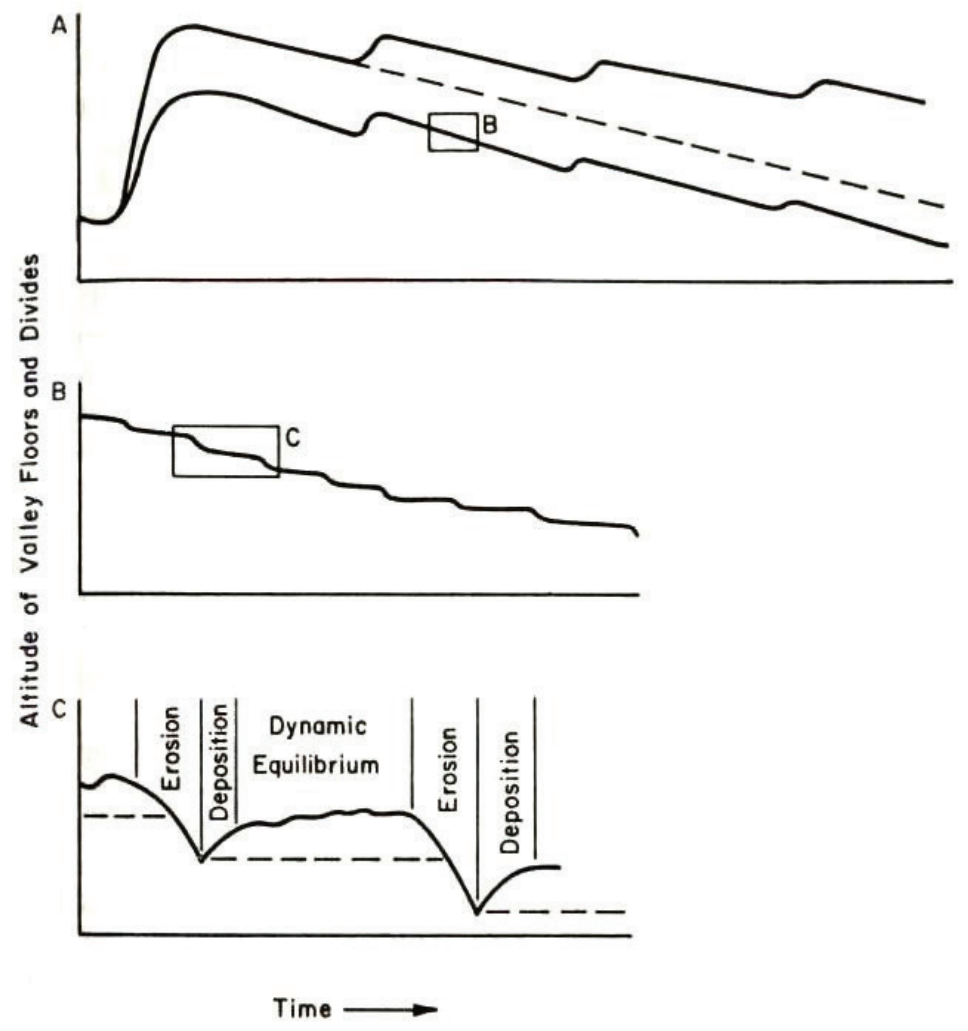

(A) Ciclo de erosão, como previsto por Davis (linha tracejada), seguindo soerguimento, e como o ajuste de denução é afetado pelo soerguimento.

(B) Porção do perfil do vale em A acima, mostrando episódio natural de decréscimo do perfil de altitude do vale.

(C) Porção do vale em B acima, mostrando os períodos de instabilidade separados por longos períodos de equilibrio dinâmico.

fonte: Schumm (1975). 
Capel (1983), em uma análise histórica, diz que o trabalho de Horton sobre o desenvolvimento da erosão em bacia de drenagem, nos anos de 1940, assim como a teoria de Strahler sobre o equilibrio das vertentes em 1950, propiciou uma corrente quantitativa que daria ênfase aos processos gerais na medida sistemática das formas superficiais simples e complexas. A busca por uma teoria de sistemas geomorfológicos em equilíbrio dinâmico se tornou uma preocupação dominante. É certo que, se havia contra-argumentações também aos esquemas davisianos, considerados excessivamente qualitativos, em contrapartida figuras de caráter claramente positivistas, como Gilbert, valorizavam o novo.

Assim, para Chorley (1962), a geomorfologia que emergiu a partir dos anos 1950 foi "uma ciência funcional clássica", com suas formas superficiais, a mesoescala, como objeto do estudo. Assim, desenvolveu-se o que Chorley havia denominado uma "geomorfologia funcional", cuja base está na tese positivista lógica de que os fenômenos do mundo real podem ser explicados com exemplos de regularidades repetidas e previsíveis, nas quais se pode aceitar a inter-relação entre forma e função. Uma teoria desse tipo deriva do ponto de vista que a ciência está empiricamente baseada, racional, objetiva e dirigida a facilitar explicações e previsões sobre a base das relações regulares observadas.

Dessa forma, também adquirem importância as técnicas de correlação estatística "derivadas - assinala Chorley - como necessidade lógica, contrariamente às crenças generalizadas das bases teóricas do funcionalismo e não vice-versa". Essas técnicas surgem em conjunto, logicamente com uma exaltação e magnificação da estatística, do uso do computador e a busca de novas técnicas de análises matemáticas e geométricas.

Entre os autores que se baseiam na Teoria do equilibrio dinâmico para seus estudos se destacam: Casseti (1990), Cruz (1998), Christofoletti (1990), Tricart (1977), Tricart e Kiewiet de Jonge (1992), Ross (1994) e Colângelo (1995).

Em sua interpretação, Casseti (1990) denomina "o sistema de J. Hack" e afirma que Hack seria o autor que mais trabalhou com o conceito de equilíbrio dinâmico e que esse conceito fundamenta-se na teoria geral dos sistemas, a qual foi incorporada na linhagem da escola anglo-americana. Sintetiza ainda que toda alternância de energia, externa ou interna, implica alteração no sistema por meio da matéria, razão pela qual todos os elementos da morfologia tendem a se ajustar em função das modificações impostas, seja pelas forças tectodinâmicas, seja pelas mudanças processuais subaéreas (mecanismos morfoclimáticos). Diante disso, conclui-se que a morfologia não tenderia necessariamente para o aplainamento (princípio da equifinalização), ou seja, que o equilíbrio pode ocorrer sob os mais variados panoramas topográficos, como afirmou Hack (1960) (Figura 3). 
Figura 3 - Equilíbrio dinâmico mantido nos diferentes panoramas topográficos, determinado pela diferencial litológica que, mesmo em fortes declives, propicia um volume de material correspondente

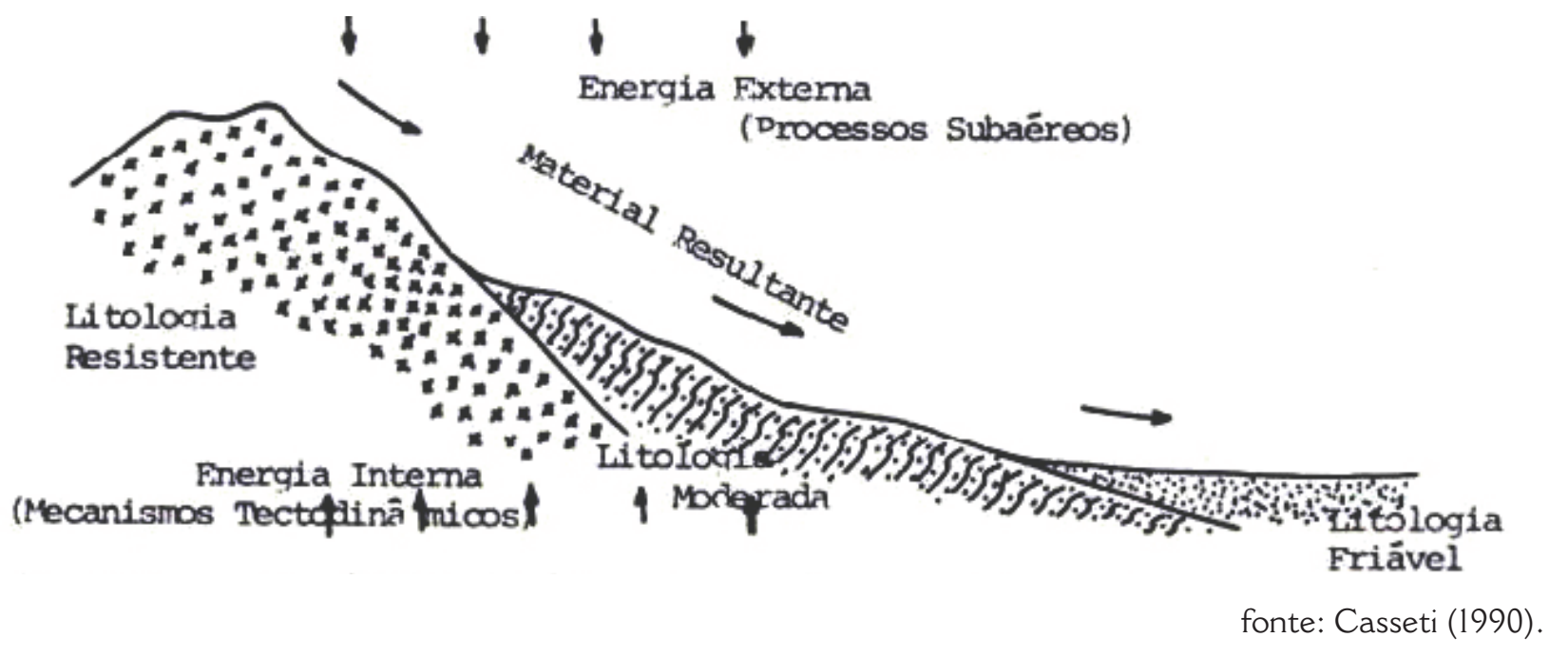

Casseti (1990) finaliza concordando com as ideias de Hack de que as formas do relevo e os depósitos superficiais possuem uma íntima relação com a estrutura geológica (litologia). Verificou ainda que a declividade dos canais fluviais diminui com o comprimento do rio e que varia em função do material e que o equilibrio é alcançado quando a intensidade média de erosão dos diferentes compartimentos de uma paisagem é a mesma.

Contudo, deve-se observar que no equilibrio dinâmico, as formas não são estáticas. Qualquer alteração no fluxo de energia incidente tende a responder por manifestações no comportamento da matéria, evidenciando, por conseguinte, mudanças morfológicas. Como exemplo, as mudanças climáticas ou implicações tectônicas produzem mudanças no fluxo de matéria, até a obtenção de novo reajustamento dos componentes do sistema. Algo intrínseco ao argumento de Hack é a de que o modelado se adapta rapidamente às variações dos fatores de controle ambiental (Casseti, 1990, p. 34).

Apesar de não citar a origem do equilibrio dinâmico entre os autores consultados, Tricart (1977) foi um dos que conseguiu se aproximar de uma aplicação adequada aos termos do equilibrio dinâmico. Em seu livro Ecodinâmica, cria os termos relacionados às variações do relevo associados à morfogênese e à pedogênese, processos diretamente ligados ao equilibrio dinâmico das formas. Elabora os termos de classificação em unidades ecodinâmicas estáveis, instáveis e intergrades. As unidades ecodinâmicas estáveis seriam setores em que a pedogênese predomina sobre a morfogênese, ou seja, os processos pedogenéticos ocorrem naturalmente. As unidades ecodinâmicas instáveis seriam os setores em que a morfogênese se sobrepõe à pedogênese. E, por fim, as unidades ecodinâmicas intergrades, que estariam associadas a um equilibrio entre a morfogênese e a pedogênese (o que estaria associado ao equilibrio dinâmico), no qual as trocas de energia e matéria se processam naturalmente sem que existam mudanças significativas na paisagem, tanto de origem antrópica quanto causadas por condições naturais adversas; isso enfatizando a importância da cobertura vegetal nesses processos.

Conjunto de fenômenos que se processam mediante fluxos de matéria e ener- 
gia. Esses fluxos originam relações de dependência mútua entre os fenômenos. Como consequência, o sistema apresenta propriedades que the são inerentes e diferem da soma das propriedades dos seus componentes. Uma delas é ter dinâmica própria, específica do sistema (Tricart, 1977, p. 86).

Tricart trata a questão da dinâmica dos ambientes com a situação de estabilidade das geobiocenoses que eles comportam, a partir da intensidade dos processos atuais que ocorrem na área onde os solos, aliados às formas (morfodinâmica), revelam os meios estáveis e instáveis, e onde a morfogênese e a pedogênese são elementos-chave da dinâmica ambiental e o fator determinante do sistema natural, a que outros elementos estão subordinados.

Para o autor, as deformações tectônicas comandam todos os processos em que a gravidade intervém, favorecendo a dissecação das áreas elevadas, com incisão dos cursos d'água e crescimento dos declives das encostas. Os efeitos da tectônica combinam-se com os da litologia como em todos os modelados de dissecação. Nas áreas de acumulação, o abandono dos materiais é acompanhado também de instabilidade e rápida remoção.

Segundo Christofoletti (1990), a palavra equilíbrio tem diversos significados. A noção de equilibrio foi utilizada pela teoria davisiana, na suposição de que ele se estendia paulatinamente do nível de base em direção à montante, conforme o decorrer do ciclo. Essa ideia implicava que, em algumas partes da bacia, as declividades das vertentes serão relativamente mais acentuadas que as verificadas em rochas de menor resistência (folhelhos e xistos, por exemplo). Quaisquer que sejam as condições de energia, a composição litológica influencia como agente diferenciador na morfologia.

A teoria do equilibrio dinâmico possibilita revisão global da ciência geomorfológica, a começar pela definição e delimitação do objeto de estudo. Essa perspectiva também clarifica algumas das preocupações que devem envolver os pesquisadores engajados com a aplicação de técnicas quantitativas, sendo que uma das mais importantes é testar se as intensidades de degradação são iguais às diversas partes dentro das paisagens equilibradas (Christofoletti, 1990, p. 168).

Conforme Ross (1994), a quebra do equilibrio dinâmico está diretamente ligada às intervenções humanas, que afetam a fragilidade dos ambientes em função das características genéticas destes. Para o autor, os ambientes naturais mostram-se, ou mostravam-se, em estado de equilibrio dinâmico até o momento em que as sociedades humanas passaram a intervir na natureza.

A princípio, salvo algumas regiões do planeta, os ambientes naturais mostram-se ou mostravam-se em estado de equilibrio dinâmico até o momento em as sociedades humanas passaram progressivamente a intervir cada vez mais intensamente na exploração dos recursos naturais (Ross, 1994, p. 34).

Ross associa muito mais o rompimento da manutenção do equilibrio dinâmico aos eventos provocados pela atuação antrópica ao meio ambiente e propõe a metodologia da fragilidade ambiental adiante da atuação antrópica. Segundo o autor, as áreas onde está comprovada a alteração direta provocada pelo homem são classificadas como de fragilidade emergente; já onde a atuação antrópica é discreta ou invisível, as áreas são classificadas como de fragilidade potencial. Nessa metodologia, Ross $(1992,1994)$, apresenta uma série de fatores que determinam a fragilidade ambiental dos ambientes e os apresenta em forma de tabelas. As tabelas 
de fragilidade apresentam uma graduação (em cinco níveis) que classifica o fato analisado. Por exemplo, o primeiro parâmetro observado é a declividade do terreno. Dependendo do grau de declividade, poderá receber a classificação de fragilidade muito alta, alta, média, baixa e muito baixa. Para cada componente ambiental é atribuído um grau de fragilidade. Essa metodologia está melhor explicada no capítulo sobre a fragilidade ambiental.

A explicação fornecida por Hack para os Apalaches é distinta das anteriormente aventadas por vários autores, baseadas no reconhecimento de superfícies aplainadas.

A teoria do equilibrio dinâmico considera modelado terrestre como um sistema aberto, isto é, um sistema que mantém constante permuta de matéria e energia com os demais sistemas componentes de seu universo. A fim de que possam permanecer em funcionamento, necessitam de ininterrupta suplementação de energia e matéria, assim como funcionam através de constante remoção de tais fornecimentos (Christofoletti, 1990, p. 168).

Numa revisão sumária dos autores que opinaram sobre o conceito de equilibrio dinâmico, Cruz (1998) lembra que o equilibrio/desequilibrio no estudo dos conjuntos geomórficos tem sido muito discutido e que a discussão se estendeu com Mackin (1948), Davis (1909), Penck (1953) e King (1953), além de muitos outros, sobretudo a partir das acepções de quase equilíbrio, de Leopold e Maddock, em 1953, e da teoria probabilística da evolução do relevo, quando então a proposta foi renovada por Hack, em 1960, com a teoria do equilibrio dinâmico. Na teoria do equilibrio dinâmico, as formas não são estáticas. Qualquer alteração no fluxo de energia incidente tende a responder por manifestações no comportamento da matéria, evidenciando mudanças morfológicas. Como exemplo, as mudanças climáticas ou eventos tectônicos produzem mudanças no fluxo da matéria, até a obtenção de novo reajustamento dos componentes do sistema. Algo intrínseco ao argumento de Hack é que o modelado do relevo se adapta rapidamente às variações dos fatores de controle ambiental (Casseti, [2005], p. 16).

As novas concepções de estudos do relevo mais diretamente ligadas à teoria geral dos sistemas, de Bertalanffy, consideram a noção de sistema aberto e do equilibrio em diferentes escalas adotadas e passam a fazer parte da fundamentação da teoria do equilibrio dinâmico.

Nesse sentido, encontram-se, nas ideias de Lovelock (1991, p. 19-20), explicações mais fundamentadas sobre a noção de sistema como organismo, segundo as quais a própria Gaia ${ }^{3}$ manifesta um comportamento homeostático por meio do inter-relacionamento que a Terra mantém com o seu meio ambiente, a atmosfera. As inter-relações observadas nos organismos vivos agem também nos sistemas naturais, o que permite explicar a estabilidade desses sistemas. $\bigcirc$ nível de estabilidade

3 Lovelock descreve Gaia como um sistema de controle da Terra, um sistema que se autorregula, semelhante ao termostato de uma geladeira, de um ferro de engomar ou de um forno doméstico. E afirma: "O melhor que sou capaz é dizer que Gaia é um sistema evolutivo, um sistema constituído por todos os seres vivos e pelo seu ambiente de superfície, os oceanos, a atmosfera e as rochas da crosta, estando as duas partes estreitamente unidas e indivisíveis". Para Lovelock (1991, p. 621), a "teoria de Gaia vê a biota e as rochas, o ar e os oceanos como existências de uma entidade fortemente conjugada. Sua evolução é um processo único, e não vários processos separados estudados em diferentes prédios de universidades". $\bigcirc$ caráter sistêmico de Gaia é explicado por Lovelock de modo multidisciplinar. O autor afirma que ela "tem um significado profundo para a biologia. Afeta até a grande visão de Darwin, pois talvez não seja mais suficiente dizer que os indivíduos que deixarem a maior prole terão êxito. Será necessário acrescentar a cláusula de que podem conseguir contanto que não afetem adversamente o meio ambiente". De modo similar, conclui que a "teoria de Gaia também amplia a ecologia teórica. Colocando-se as espécies e o meio ambiente juntos, algo que nenhum ecologista teórico fez, a instabilidade matemática clássica de modelos de biologia populacional está curada”. 
dos sistemas é variável e depende dos fatores do ambiente, além da eficiência dos controles internos. Segundo Odum (1988, p. 29) existem "a estabilidade de resistência (capacidade de se manter estável diante do estresse) e a estabilidade de elasticidade (capacidade de se recuperar rapidamente)". Esse processo de regeneração foi também chamado de resiliência por Ehart.

As formas e os processos encontram-se em estado de estabilidade e podem ser considerados como independentes do tempo. Ela requer um comportamento balanceado entre forças opostas, de maneira que as influências sejam proporcionalmente iguais e que os efeitos contrários se cancelem a fim de produzir o estado de estabilidade, no qual a energia está continuamente entrando em saindo do sistema. $\bigcirc$ estado de estabilidade representa o funcionamento do sistema no momento em que todas as variáveis estão ajustadas em função da quantidade e variabilidade intrínseca da energia que lhe é fornecida. Assim, se houver alteração no fornecimento de energia (por exemplo, oscilação climática), o sistema reagirá a tais modificações e se desenvolverá até alcançar nova estruturação, no estado de estabilidade (Christofoletti, 1990, p. 168).

Para Christofoletti, essa argumentação se baseia no fato de que as formas de relevo e os depósitos superficiais têm uma íntima e diversificada relação com a estrutura geológica. Hack (1965) verificou que a declividade dos canais fluviais diminui com o comprimento do rio, ou seja, com a distância a partir das divisas da bacia, de acordo como tipo de rocha. Portanto, a declividade do canal em certas distâncias a partir da divisa se torna muito diferenciada em determinadas espécies de materiais.

A amplitude topográfica, a distância vertical entre o topo da vertente e fundo do vale de um rio adjacente, é aproximadamente igual dentro de determinado tipo de rocha, mas difere muito de uma litologia para outra. Do mesmo modo, os perfis das vertentes variam conforme o tipo litológico. Dessas verificações, nota-se que as diferenças topográficas entre afloramentos rochosos diferentes são "consequências das diferenças entre as formas dos perfis fluviais de tais áreas e entre as formas dos interflúvios" (Hack, 1965 apud Christofoletti, 1990, p. 169).

A teoria do equilibrio dinâmico está relacionada ao tratamento do modelado terrestre dentro da perspectiva analítica dos sistemas abertos. A exposição das várias propriedades inerentes aos sistemas abertos auxilia a melhor compreensão do equilibrio dinâmico. Dessa forma, Richard J. Chorley (1962 apud Christofoletti, 1990) destaca as propriedades que aqui se seguem.

O sistema aberto pode atingir o equilibrio dinâmico, no qual a importação e a exportação de energia e de matéria são equacionadas por meio de um ajustamento das formas, ou geometria do próprio sistema. Assim, o gradiente dos canais fluviais é ajustado à quantidade de água e carga e à resistência do leito, de tal modo que o trabalho seja igual em todas as partes do curso. Esse ajustamento é conseguido por causa da capacidade de autorregulação, e como há interdependência entre os elementos de todo o sistema, qualquer alteração que se processa em um segmento fluvial será paulatinamente comunicada a todos os demais elementos fluviais. E como um membro do sistema pode influir em todos os outros, cada um dos membros pode ser influenciado por qualquer outro. Alguns autores consideram que o equilibrio não é alcançado de modo global em um sistema que está sofrendo contínuas mudanças, como é o caso de paisagens em processo de degradação (Figura 4). 
Figura 4 - Equilíbrio dinâmico

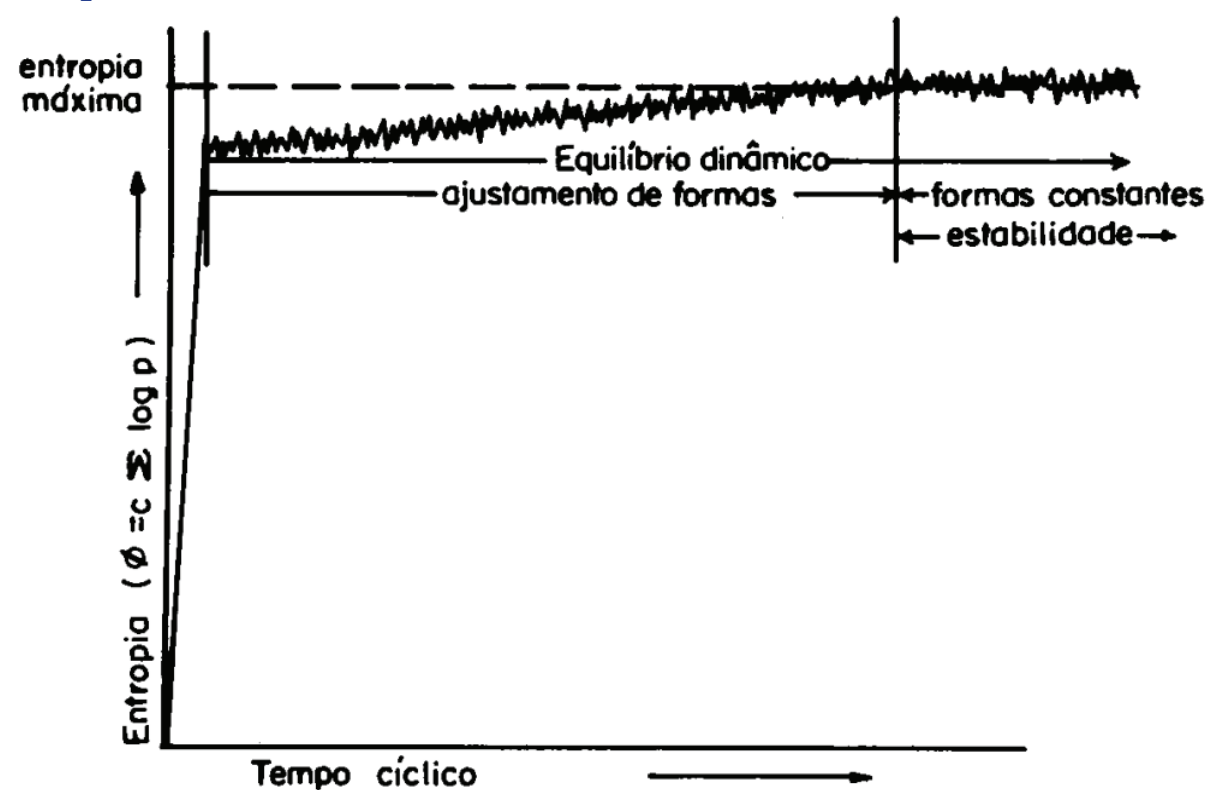

fonte: Langbein e Leopold (1964).

A designação quase-equilíbrio foi proposta por Langbein e Leopold, (1964 apud Christofoletti, 1990) para expressar essa situação. Já Abrahams (1968) distingue entre equilibrio dinâmico e estado de estabilidade, observando que esse último é um subconjunto do primeiro (Figura 5).

Figura 5 - Perfis fluviais esquemáticos para determinada amplitude altimétrica, considerando as tendências do desgaste uniforme de energia e do trabalho total mínimo (segundo Langbein; Leopold, 1964)

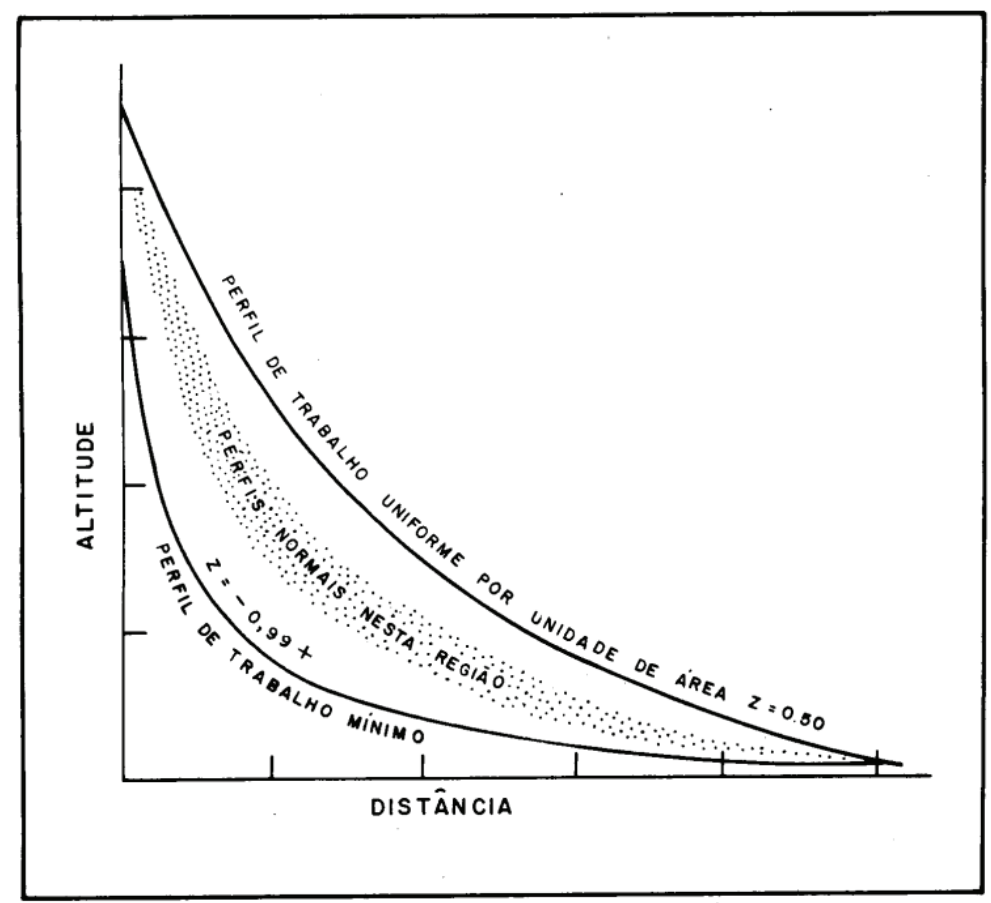


Em crítica ao conceito de equilibrio dinâmico, utilizado como termo de quase equilíbrio, Thorn e Welford (1994) concordam com os argumentos de Schumm e Lichty (1965) e Schumm (1975), que se resumem à comparação de equilibrio dinâmico com estado estável proposto por Hack (1960), mas que, segundo Hack (1960) e Chorley (1962), devem ter deixado perplexos alguns geomorfólogos por rejeitar a dimensão do tempo, na qual está o maior interesse do geólogo. A discussão que se segue é uma atenção para mostrar que a sugestão de Hack e Chorley não era necessariamente uma quebra com a tradição, mas simplesmente um método de consideração da paisagem com extensos limites temporais.

$\bigcirc$ equilibrio dinâmico demonstra que os aspectos das formas não são estáticos e imutáveis, mas mantidos pelo fluxo de matéria e energia que atravessa o sistema. Com o passar do tempo, a massa da paisagem será removida e implicará mudanças progressivas em algumas propriedades geométricas, como no decréscimo do relevo médio, desde que não haja nenhuma compensação tectônica. Todavia, é errôneo acreditar que todas as demais propriedades devem responder de maneira simples a essa alteração progressiva, sequencial. $\bigcirc$ princípio do tamanho ótimo daquele sistema vigorará muito tempo e não será sempre suscetível às mudanças sucessivas e sequências. Geralmente, altera-se uma das variáveis externas (os fatores que controlam o fluxo de massa e energia para o sistema).

Entretanto, pode ocorrer que modificações sensíveis nos fatores controladores sejam absorvidas pela própria estruturação do sistema, desde que essas oscilações não ultrapassem os limites que interfiram no equilibrio interno do todo. A densidade hidrográfica e a estruturação das redes de drenagem podem permanecer as mesmas através de oscilações paleoclimáticas, como na sucessão de fases secas e úmidas das áreas intertropicais.

Quando o sistema atinge o equilíbrio dinâmico, desaparece a influência das condições iniciais e muitos traços das paisagens anteriores já foram destruídos. Quando se analisam fenômenos com acentuada tendência para o equilibrio dinâmico, o tratamento histórico torna-se hipotético e inútil. Por exemplo, o soerguimento pode continuar indefinidamente e, se o entalhamento e a denudação acompanharem o mesmo ritmo, a paisagem e as formas relíquias, formadas sob condições passadas diferentes, são preservadas somente se o equilibrio dinâmico ainda não foi atingido. Essa consideração não significa que as formas relíquias sejam raras na superfície terrestre, mas o critério de análise incide sobre a harmonia e o equilibrio entre os processos atuais e as formações rochosas. A geometria hidráulica dos canais fluviais responde prontamente às mudanças das precipitações, mas a rede de drenagem e as formas topográficas têm inércia muito maior (Christofoletti, 1990).

A última característica assinala que os sistemas abertos são capazes de atingir a equifinalização, isto é, condições iniciais diferentes podem conduzir a resultados finais semelhantes. Esse conceito acentua a natureza multivariada da maioria dos processos morfogenéticos e é contrário ao tratamento unidirecional da abordagem evolutiva cíclica de Davis.

Com relação à influência climática sobre o modelado, Marques (1990, p. 33) destaca que a aplicação conceitual do equilibrio dinâmico nos estudos morfoclimáticos não levaria, necessariamente, também a uma homogeneidade da forma quando o relevo é submetido a um mesmo clima. As formas passam a representar o resultado contínuo de um ajuste entre o comportamento dos processos e o nível de resistência oferecido pelo material que está sendo 
trabalhado. As formas do relevo deixam de ser algo estático para ser também dinâmicas em suas tendências a um melhor ajuste, em sintonia com um processo que pode levar ao aparecimento de diferentes formas.

Portanto, entende-se que a fragilidade de um ambiente está diretamente relacionada aos processos de interferência nesse equilibrio dinâmico de trocas do sistema natural. Por equilibrio dinâmico entende-se serem as trocas de energia e de matéria necessárias para o desenvolvimento dos processos que regem o sistema natural, quando estes atingem um estágio em que as mudanças são somente percebidas em escala de tempo geológico. Quando essas mudanças no estado de equilibrio dinâmico estável são percebidas na escala humana, considera-se que o sistema está em estado de equilibrio dinâmico instável.

Quando é possível conhecer a estabilidade de um sistema, ou se o sistema se encontra em equilibrio dinâmico, é possível determinar o seu grau de fragilidade diante das mudanças adversas, inclusive as antrópicas.

Segundo Christofoletti (1999, p. 113), para uma avaliação das possibilidades de mudanças é necessário conhecer a estabilidade dos sistemas, cujo processo de reajuste interno implica um circuito de retroalimentação. Isso porque os sistemas ambientais, em relação a sua estrutura e funcionalidade, alcançam um estado de equilibrio, caracterizados por uma organização ajustada às condições das forças controladoras.

A noção de estabilidade aborda dois aspectos: o primeiro refere-se à inércia, que é o estado em que o sistema permanece sem ser alterado pelos distúrbios externos, na qual as oscilações das forças controladoras não modificam o sistema, e o segundo refere-se á resiliência, que é a capacidade do sistema em retornar ao seu estado original depois de ser afetado pela ação dos distúrbios externos. Esses dois conceitos são importantes ao planejamento e à gestão ambiental, porque evidenciam o comportamento dos sistemas e o grau de estabilidade em relação a sua manutenção ou rápida recuperação após implantação de efeitos perturbadores, permitindo a avaliação do grau das consequências do impacto ambiental e antropogênico (Christofoletti, 1999, p. 114).

De acordo com Thorn e Welford (1994), a dinâmica é fundamentada nas leis do movimento de Newton, segundo as quais $F$ (força) é o tempo de aceleração da massa, que altera a velocidade de um objeto e é expressa em termos de massa (M), comprimento (L) e tempo (T): $\mathrm{F}=\mathrm{MLT}^{-2}$. Essa relação conduz, em mudança, à definição de equilibrio: "quando a velocidade de um objeto é constante, ou se o objeto está em repouso, isso é dizer que está em equilibrio" (Serway; Faughn, 1992, p. $75^{4}$ apud Thorn; Welford, 1994).

Cada definição de equilibrio não implica que não existe uma força agindo no objeto, mas, preferencialmente, que a soma dos vetores é zero, ou $\sum i F i=0$ (Blatt, 1988, p. 56). Essa "primeira condição de equilibrio" prova um caminho muito utilizado de equilibrio conceitualizado chamado de "a ausência de aceleração" (Frautschi et al., 1986, p. 121). Se um corpo está estacionado ou em repouso, considera-se que se encontra em equilibrio estático (Halliday; Resnick, 1981; Giancoli, 1985 apud Thorn; Welford, 1994). Se o corpo encontra a primeira condição para o equilibrio e está movendo dentro da estrutura de referência, pode estar em equilibrio dinâmico (Haliday; Resnick, 1981; Giancoli, 1985 apud Thorn; Welford, 1994). Em

4 SERWAY, R. A.; FAUGHN, J. S. College Physics. 3rd ed. Fort Worth, TX: Saunders College Publishing, 1992. 
dinâmicas, a distinção entre equilibrio estático e equilibrio dinâmico não apresenta problema, porque equilibrio dinâmico deve ser convertido simplesmente pela mudança de referência da estrutura, isto é, o observador e o objeto se movem juntos.

A termodinâmica reconhece três tipos de sistemas: sistemas isolados assumem que as bordas são fechadas para importação e exportação de massa, mas não de energia; sistemas fechados assumem que os limites previnem a importação e exportação de massa, mas não de energia; e os sistemas abertos assumem uma troca de ambas, massa e energia, com seus arredores (Parker; Jenny, 1945, p. 1158). A definição de equilibrio varia com cada tipo de sistema e isso serve para aquelas definições que se utilizará novamente agora.

\section{Considerações finais}

Na verdade, a teoria do equilibrio dinâmico, assim como outras, vem sendo moldada de acordo com as críticas construtivas que muito concorrem para os estudos relacionados aos princípios básicos propostos por Davis com enfoque geomorfológico. Esses princípios foram sendo aprimorados e hoje são considerados fundamentais nos estudos do relevo, já que as formas, a função, a estrutura e os processos constituem elementos chave na interpretação da evolução das formas do relevo e no entendimento das teorias que estão diretamente relacionadas ao estudo da gênese das paisagens.

Embora o equilibrio dinâmico tenha sido tratado superficialmente por alguns autores, a retomada da literatura sobre o assunto nos ajudou a entender melhor essa teoria no contexto dos processos geomorfológicos.

Apesar de muito criticada, a teoria do ciclo geomórfico deixou marcas profundas na história do desenvolvimento da geomorfologia. Até os dias atuais, por mais simples que sejam, suas considerações e ponderações sempre perpassam as grandes discussões. Por mais restritiva que tenha sido, se reconhece de sua importância; ela muito contribuiu para o surgimento de novos pensamentos e proposições mais atuais ou ao menos aplicáveis em níveis mais variados de formação e manutenção dos processos formadores do relevo.

As considerações aventadas sobre cada contribuição no decorrer do desenvolvimento e tratamento teórico da geomorfologia devem contemplar o conhecimento factual, como recorda Christofoletti (1980). Essa questão se refere ao estudo das características e dos mecanismos dos processos e das formas, fornecendo elementos que permitem reconhecer seu funcionamento em todas as etapas. A função de descrever os mecanismos e as formas é, por si mesma, neutra, sem significação.

A teoria do equilíbrio dinâmico tem se mostrado de grande importância para a geomorfologia atual. Muitos de seus fundamentos são usados no argumento de que a falta de equilibrio dinâmico que consideramos pode ser entendida como desenvolvimento natural de um sistema e estar associada a mudanças naturais ou artificiais. Quando esse sistema sofre intervenções, sejam elas de ordem antrópica ou natural, interrompe-se esse equilíbrio dinâmico, que passa a ser momentaneamente instável. Nesse momento não há equilibrio, apenas a dinâmica em atuação, que funcionará de maneira diferente até que se volte ao estado equilibrado e se desenvolva naturalmente. A volta ao seu estado natural dependerá do conjunto formado pelo material que sustenta esses sistemas, dos processos nele atuantes, bem como do clima. 


\section{Referências}

ABRAHAMS, A. D. Distinguishig between the concepts of steady state and dynamic equilibrium in Geomorphology. Earth Science Journal, v.2, n. 2, p. 160-166, 1968.

BLATT, M. R.; CLINT, G. M. Mechanisms of fusicoccin action: kinetic modification and inactivation of $\mathrm{K}(+)$ channels in guard cells. Planta, v. 178, n. 4, p. 509-523, 1988.

BULL, W. Landforms that that do not tend toward a steady state. In: MELHORN, W. N.; FLEMAL, R. C. (Org.). Theories of landform development. London: Allen E Unwin, 1975. p. 111-128.

CASSETI, V. Geomorfologia. [s.l.]: [2005]. Disponível em: <http://www.funape.org.br/ geomorfologia/>. Acesso em: 10 dez. 2015.

Elementos de Geomorfologia. Goiânia: UFG, 1990.

Estudo dos efeitos morfodinâmicos pluviais no planalto de Goiânia: uma análise quantitativa de resultados experimentais. Tese (Doutorado em Geomorfologia) - Faculdade de Filosofia, Letras e Ciências Humanas, Universidade de São Paulo, São Paulo, 1983.

CAPEL, H. Positivismo y antipositivismo en la ciencia geográfica: el ejemplo de la geomorfología. Geo Crítica, Universidad de Barcelona, n. 43, p. 1-56, 1983.

CHORLEY, R. J. Handling Geographic Information. Report of the Committee of Enquiry chaired by Lord Chorley. London: Department of Environment, 1987.

. Geomorphology and general systems theory. Geology Survey Prof. Paper 500-B. Washington DC, p. 1-10, 1962.

; HAGGETT, P. Trends-surface mapping in geographical research. The Royal Geographical Society, London, n. 37, p. 47-67, 1965.

; KENNEDY, B. A. Physical geography: a systems approach. London: Prentice Hall International, 1971.

CHRISTOFOLETTI, A. Modelagem de sistemas ambientais. São Paulo: Edgard Blucher, 1999.

A geografia física no estudo das mudanças ambientais. In: BECKER, B. et al. (Org.).

Geografia e meio ambiente no Brasil. São Paulo: Hucitec, 1990, p. 334-345.

- Significância da teoria de sistemas em geografia física. Boletim de Geografia Teorética, Rio Claro, v. 16-17, n. 31-34, p. 119-128, 1986-1987.

Geomorfologia fluvial. São Paulo: Edgard Blucher, 1981.

As teorias geomorfológicas. In: Geomorfologia. 2. ed. São Paulo: Edgard Blucher, 1980. p. 159-76.

Análise de sistemas em geografia. São Paulo: Hucitec, 1979.

As tendências atuais da geomorfologia. Notícia Geomorfológica, Campinas, v.

17, n. 33, p. 35-91, jun. 1977. 
. Geomorfologia. São Paulo: Universidade de São Paulo, 1974.

COLÂNGELO, A. C. Os mecanismos de compensação e o equilibrio de forças na dinâmica dos materiais de vertente. Revista do Departamento de Geografia, São Paulo, n. 9, p. 13, 1995.

CRUZ, O. A ilha de Santa Catarina e o continente próximo: um estudo de geomorfologia costeira. Florianópolis: Ed. da UFSC, 1998.

DANIELS, R. B.; HAMMER, R. D. Soil geomorphology. New York: John Wiley E Sons, 1992.

DAVIS, W. M. The progress of geography in the schools. Geographical essays. Boston/ New York: Ginn and Company/Dover, 1909.

The geographical cycle. The Geographical Journal, London, v. 14, n. 5, p. 481504, nov. 1899.

FRAUTSCHI, S. C. et al. The Mechanical Universe: Mechanics and Heat Advanced. Cambridge: Cambridge University Press, 1986.

GIANCOLI, D. C. Física: principios y aplicaciones. Barcelona: Reverté, 1985.

GILBERT, G. K. Lake Bonneville. Washington DC: Government Printing Office, 1890.

Report on the geology of the Henry Mountains. Washington: Government Printing Office, 1877.

GREGORY, K. J. A natureza da geografia física. Rio de Janeiro: Bertrand Brasil, 1992.

HACK, J. T. Dynamic equilibrium and landscape evolution. In: MELHORN, W. N.; FLEMAL, R. C. (Ed.). Theories of landform development. London: Allen $\mathcal{E}$ Unwin, 1975. p. 87-102.

Stream-profile analysis and stream-gradient index. Journal of Research of the US Geological Survey, v. 1, n. 4, p. 421-429, 1973. . Interpretation of erosional topography in humid temperate regions. American Journal of Science, Bradley, v. 258, p. 80-97, 1960.

HALIDAY, D.; RESNICK, R. Conceptual and theoretical aspects of human exposure and dose assessment. Journal of Exposure Analysis and Environmental Epidemiology, v. 4, n. 3, p. 253-285, 1981.

HIGGINS, C. G. Theories of landscape development: a perspective. In: MELHORN, W. N.; FLEMAL, R. C. (Ed.). Theories of landform development. London: Allen E Unwin, 1975. p. 1-28.

HUMBOLDT, A. Cosmos: essai d'une description physique du monde. Trad. Charles Galusky. Paris: Gide et J. Baudry, 1848-1862. 4 v.

KING, C. A. M. Some problems concerning marine planation and formation of erosion surface.

Transactions Institute of British Geographers, v. 33, p. 29-43, 1953. 
KING, L. C. Canons of Landscape Evolution. Geological Society of America Bulletin, v. 64, p. 721-732, 1953.

LANGBEIN, W. B.; LEOPOLD, L. B. Quasi-Equilibrium States in Channel Morphology. American Journal of Science, v. 262, p. 782-794, June 1964.

LEOPOLD, L. B.; LANGBEIN, W. B. The Concept of Entropy in Landscape Evolution, U.S. Geological Survey Professional Paper 500-A, 1962.

LEOPOLD, L. B.; MADDOCK, T. JR. The Hydraulic Geometry of Stream Channels and Some Physiographic Implications, U.S. Geological Survey Professional Paper 252, 1953.

LOVELOCK, J. E. Gaia: A planetary emergent phenomenon. In: THOMPSON, W. Gaia 2: Emergence The New Science of Becoming. New York: Lindsfarne, 1991. p. 10-49.

MACKIN, J. H. Concept of the graded river. Geological Society of America Bulletin, v. 59, p. 463-512, 1948.

MARQUES, R. C. C. Algumas considerações a respeito da evolução do litoral paranaense e dos caracteres morfoaltimétricos das planícies de restingas. Tese (Doutorado em Engenharia) - Escola de Engenharia, Universidade Federal do Paraná, Curitiba, 1990.

MORISAWA, M. Tectonics and geomorphic models. In: MELHORN, W. N.; FLEMAL, R. C. (Ed.). Theories of landform development. London: Allen \& Unwin, 1975. p. $199-216$.

Streams: their dynamics and morphology. New York: McGraw-Hill Book Company, 1965.

ODUM, E. P. Ecologia. Rio de Janeiro: Discos CBS (interamericana), 1988.

ORME, A. R. Temporal variability of a summer shorezone. In: THORN, C. E. (Ed.). Space and time in geomorphology. London: Allen E Unwin, 1982. p. 285-314.

PARKER, E. R.; JENNY, H. Water infiltration and related soil properties as affected by cultivation and organic fertilization. Soil Science, n. 60, p. 353-376, 1945.

PENCK, W. Morphological analysis of landforms: a contribution to physical geology. London: MacMillan, 1953.

ROSS, J. L. S. Análise empírica da fragilidade dos ambientes antropizados. Revista do Departamento de Geografia, São Paulo: FFLCH /USP, n. 8, p. 63-74, 1994.

registro cartográfico dos fatos geomorfológicos e a questão da taxonomia do relevo. Revista do Departamento de Geografia, São Paulo: FFLCH-USP, n. 6, p. 17-29, 1992.

SCHUMM, S. A. Episodic erosion: a modification of the geomorphic cycle. In: MELHORN, W. N.; FLEMAL, R. C. (Org.). Theories of landform development. London: Allen E Unwin, 1975. p. 69-86. 
; LICHTY, R. W. Time, space, and causality in geomorphology. American Journal of Science, New Haven, v. 263, p. 110-119, 1965.

STRAHLER, A. N. Equilibrium theory of erosional slopes approached by frequency distribution analysis - Part I. American Journal of Science, New Haven, v. 248, p. 673696, 1950a.

. Equilibrium theory of erosional slopes approached by frequency distribution analysis

- Part II. American Journal of Science, New Haven, v. 248, p. 801-814, 1950 b.

THORN, C. E. (Ed.). Space and time in geomorphology. London: Allen \& Unwin, 1982.

; WELFORD, M. R. The equilibrium concept in geomorphology. Annals of the Association of American Geographers, v. 84, n. 4, p. 666-696, 1994.

TRICART, J. A geomorfologia e o pensamento marxista. São Paulo: Território Livre, 1980.

. Ecodinâmica. Rio de Janeiro: Supren/IBGE, 1977.

. Principes et méthodes de la géomorphologie. Paris: Masson, 1965.

. Tendências atuais da geomorfologia. In: GEORGE, P;

Visitas de mestres

franceses. Rio de Janeiro: CNG/IBGE, 1963. p. 1-22.

; KIEWIET DE JONGE, C. Ecogeography and rural management. Essex, UK:

Longman Scientific \& Technical, 1992. 